\title{
AN UNUSUAL PRESENTATION OF CHRONIC ECTOPIC PREGNANCY
}

\author{
Geetha $\mathrm{K}^{1}$, Jamila Hameed ${ }^{2}$, Seethalakshmi B ${ }^{3}$, Madhumitha $\mathrm{S}^{4}$
}

\section{HOW TO CITE THIS ARTICLE:}

Geetha K, Jamila Hameed, Seethalakshmi B, Madhumitha S. "An Unusual Presentation of Chronic Ectopic Pregnancy". Journal of Evolution of Medical and Dental Sciences 2014; Vol. 3, Issue 16, April 21;

Page: 4241-4244, DOI: $10.14260 /$ jemds/2014/2425

ABSTRACT: Implantation of the fertilized ovum outside the uterine cavity is called ectopic pregnancy. It is associated with adverse outcome if not treated earlier. The fate of ectopic pregnancy depends on many factors. Important among them being site and duration of ectopic pregnancy. The main serious outcome is rupture. If the ectopic pregnancy ruptures and the patient survives this catastrophe, the ectopic mass gets organized and presents as pelvic mass with pain. Treatment is removal of that mass which is very difficult because of inflammation and subsequent adhesions. Here we are presenting a case of gravida 4 with puerperal sterilisation done $1^{1 / 2}$ years back came with the history of 40 days amenorrhea, pelvic pain and vaginal bleeding. USG revealed a left adnexal mass of about 5.7 × 4.4 × $2.8 \mathrm{cms}$. Laparotomy was proceeded with and total salpingectomy was done. We have decided to report this case because cornual pregnancies cause disastrous effect on the patient. This case was managed successfully using modified Coffey's suspension.

KEYWORDS: Chronic ectopic, total salpingectomy, modified Coffey's suspension.

INTRODUCTION: The blastocyst normally implants in the endometrial cavity. Implanting else-where is called Ectopic pregnancy. 95\% of the ectopic implant in the fallopian tube of which most common is ampullary end. Nowadays it is more common because of artificial reproductive techniques and due to pelvic infection. The mortality is $5 \%$ due to tubal rupture.

CASE REPORT: A 28 years old Gravida 4, Para-3, Live -3, with puerperal sterilization done 1/2 years back came with the complaints of pain in the lower abdomen with vaginal spotting and burning micturition. She was lactating her $1 \frac{1}{2}$ year old baby. She established her periods after 6 months of delivery with irregular cycles.

Her LMP was 40 days back. Her pulse was 100/min. B.P. was 90/70mm Hg. She was febrile, abdomen was soft and tender in the left iliac fossa. Her Hemoglobin was $7 \mathrm{~g} / \mathrm{dl}$. Urine pregnancy test was positive and other investigations were normal. $\beta$-hCG:5000 IU/ L initially and after 48 hrs. was $5500 \mathrm{IU} / \mathrm{L}$. USG report showed heterogenous mass of $(5.7 \mathrm{X} 4.4 \mathrm{X} 2.8) \mathrm{cm}$ in the left adnexa with solid and cystic areas suggestive of tubo-ovarian mass.

Provisional diagnosis of tubo-ovarian mass suspecting chronic ectopic was made and exploratory laparotomy was done.

Intra-operative findings: There was a tubo-ovarian mass of size $6 \mathrm{X} 4 \mathrm{cms}$. at the site of left cornua adherent to the left ovary and the adnexa and neighboring structures (Figure1). 


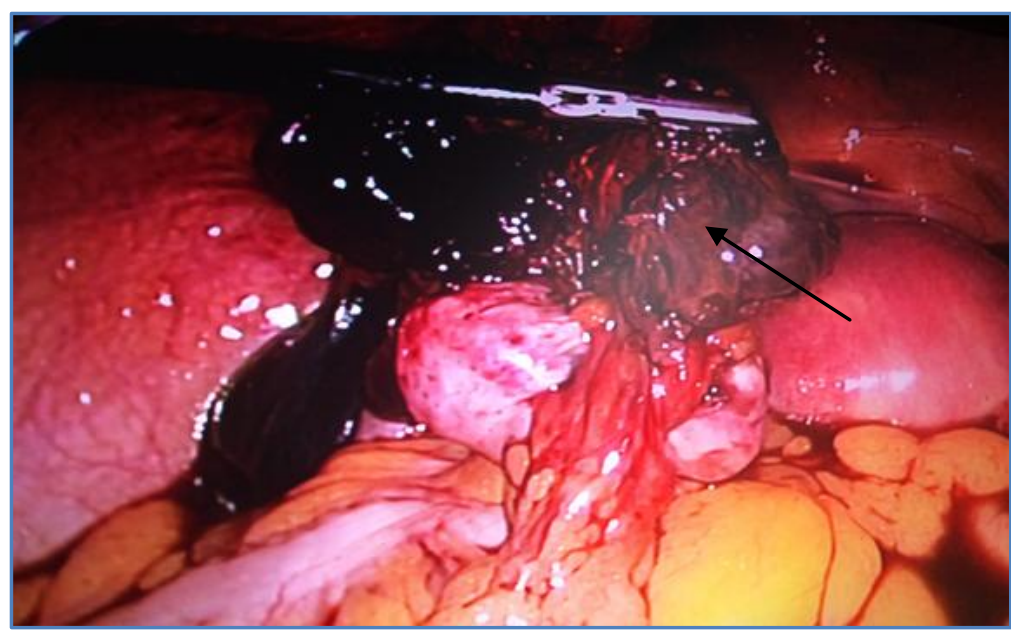

Figure 1: Chronic Tubal Pregnancy

The mass with the tube was excised by cutting a small myometrial wedge at the uterine cornua. Care was taken to avoid deep incision into the myometrium. Delayed absorbable suture material was used. The wound was peritonised by bringing the round ligament and the broad ligament over the site.

Modified Coffey suspension was done. Total salpingectomy was done on the left side. The ovary was not removed. Clotted blood amounting to $500 \mathrm{ml}$ was present which was sucked out. 2 units of blood transfusions were given. Post-operative period was uneventful. She was discharged in good condition. Histopathological examination of the mass confirmed the presence of chorionic villi.

DISCUSSION: Tubal rupture with severe intraperitoneal hemorrhage may lead to severe morbidity or mortality. Incidence of rupture is $20-35 \% .^{1}$

Mortality rate for ectopic pregnancy is $5 \%$ of maternal deaths in developed countries according to W.H.O.

In chronic ectopic, the $\beta$-hCG level is static while in acute rupture it is very high ${ }^{2}$. Because it was a chronic ectopic the trophoblastic tissue had died off very early and $\beta$-hCG level was very low. But in acute ectopic, the trophoblastic tissue will be healthy and will not result in early bleeding and patient can come with rupture and hemodynamic instability.

The triad, namely amenorrhea, pain, vaginal bleeding are not constant symptoms, that secure the diagnosis with reliability. ${ }^{3}$ Diagnostic laparoscopy is the gold standard for hemodynamically stable patient with $\beta$-hCG $>2000$ IU/L with no sonographic evidence of intrauterine pregnancy. Regarding ectopic tubal pregnancy, it can end up in tubal rupture, tubal abortion or spontaneous resolution.

There are plenty of studies that compared open laparotomy and laparoscopic surgeries for ectopic ${ }^{4}$. Conservative line of management with methotrexate is indicated when the ectopic pregnancy size is $<4 \mathrm{~cm}$ without cardiac activity or $<3.5 \mathrm{~cm}$ with cardiac activity and $\beta$-hCG level $<$ $5000 \mathrm{IU} / \mathrm{L}$. Regarding the expectant therapy, spontaneous resolution of ectopic is noted in $64 \%$ of patients. ${ }^{5}$

Resolution is possible when initial $\beta$-hCG concentration is $<1000 \mathrm{IU} / \mathrm{L}$ and hemoperitoneum $<50 \mathrm{ml}$ with a hematosalpinx of $<2 \mathrm{~cm}$. Subsequent studies done by Kor and colleagues show 
decreasing $\beta$-hCG levels, absent intact pregnancy by TVS and an adnexal mass of $<4 \mathrm{~cm}$ without an embryonic heartbeat. ${ }^{6}$ In his studies $65 \%$ had spontaneous resolution of ectopic and the rest had surgery for rising $\beta$-hCG levels.

According to Seifer factors that increase the risk of persistent ectopic pregnancy are:

1. Small pregnancy less than $2 \mathrm{~cm}$,

2. Implantation medial to salpingostomy site,

3. $\beta$-hcg levels exceeding $3000 \mathrm{mI} \mathrm{U} / \mathrm{ml}^{7}$.

Radical approach of total salpingectomy is usually followed in A) tubal rupture with hemoperitoneum B) recurrent ectopic pregnancy in severely damaged tube and C) in a patient who has completed her family. Laparoscopy is done in patients who are hemodynamically stable.

Total salpingectomy with partial cornual resection has been criticized for providing a residual sinus tract that allows development of subsequent interstitial pregnancy and this does not occur if the peritonisation of the cornual site is done with the round ligament (Modified Coffey's suspension). Residual myometrial defect may cause uterine rupture or interstitial pregnancy.

This is avoided if resection is less than $1 / 3^{\text {rd }}$ of the thickness of the cornual portion of the myometrium.

CONCLUSION: Rupture of cornual pregnancy leads to torrential hemorrhage and collapse of the patient if not diagnosed in time. This case was diagnosed and managed by modified Coffey's suspension to avoid unwanted sequelae in future.

\section{REFERENCES:}

1. Job-Spira N, Fernandez H, Boyer J et al. Ruptured tubal ectopic pregnancy: risk factors and reproductive outcome: results of a population-based study in France. Am J Obstet Gynecol 1999:180(4):938-44.

2. Barnhart KT, Rinaudo P, Hummel A et al. Acute and chronic presentation of ectopic pregnancy may be two clinical entities. Fertil Steril. 2003; 80(6):1345-51.

3. Dart RG, Kaplan B, Varaklis K. Predictive value of history and physical examination in patients with suspected ectopic pregnancy. Ann Emerg Med. 1999; 33(3):283-90.

4. Lundorff $\mathrm{P}$, Thorburn J, Hahlin $\mathrm{M}$ et al. Laparoscopic surgery in ectopic pregnancy. A randomized trial versus laparotomy. Acta Obstet Gynecol Scand. 1991; 70(4-5):343-8.

5. Fernandez H, Yves Vincent SC, Pauthier S et al. Randomised trial of conservative laparoscopic treatment and methotrexate administration in ectopic pregnancy and subsequent fertility. Hum Reprod. 1998; 13(11):3239-43.

6. Korhonen J, Stenman UH, Ylostalo P. Low-dose oral methotrexate with expectant management of ectopic pregnancy. Obstet Gynecol . 1996; 88(5):775-8.

7. Seifer DB. Persistent ectopic pregnancy: an argument for heightened vigilance and patient compliance. Fertil Steril. 1997; 68(3):402-4. 


\section{CASE REPORT}

\section{AUTHORS:}

1. Geetha K.

2. Jamila Hameed

3. Seethalakshmi B.

4. Madhumitha S.

\section{PARTICULARS OF CONTRIBUTORS:}

1. Assistant Professor, Department of Obstetrics and Gynaecology, VMMC \& H, Karaikal.

2. Professor, Department of Obstetrics and Gynaecology, VMMC \& H, Karaikal.

3. Lecturer, Department of Obstetrics and Gynaecology, VMMC \& H, Karaikal.
4. $1^{\text {st }}$ Year Post Graduate, Department of Obstetrics and Gynaecology, VMMC \& $\mathrm{H}$, Karaikal.

\section{NAME ADDRESS EMAIL ID OF THE CORRESPONDING AUTHOR:}

Dr. K Geetha,

Nandhu Clinic, \# 18/A,

Elaikara Street,

Karaikal - 609602.

E-mail: vemsrigeenan3@gmail.com

Date of Submission: 11/03/2014.

Date of Peer Review: 12/03/2014.

Date of Acceptance: 28/03/2014.

Date of Publishing: 16/04/2014. 